\title{
Sex determination in the hymenopteran Diadromus pulchellus (Ichneumonidae): validation of the one-locus multi-allele model
}

\author{
G. PERIQUET, M. P. HEDDERWICK, M. EL AGOZE* \& M. POIRIÉ \\ Institut de Biocénotique Expérimentale des Agrosystèmes, Faculté des Sciences, Parc Grandmont 37200 Tours, France
}

\begin{abstract}
Males of the hymenopteran Diadromus pulchellus are normally haploid, but diploid males can be obtained by inbreeding. Inbred crosses within strains that are polymorphic at the enzymatic loci $P g m-2$ and $A o-4$ or that differ by a body colour mutation produce heterozygous diploid males in offspring. The genotypic distributions observed in such progeny were compared with expected results under the one-locus sex determination model or the two independent loci model. The results show that only the one-locus multi-allele model fits the data and allow a provisional estimate of $\sim 15$ sex alleles. These conclusions generalize the case of existence of a single locus to determine sex in Hymenoptera and are discussed at the evolutionary level.
\end{abstract}

Keywords: Diadromus pulchellus, enzymatic polymorphism, genetics, Hymenoptera, sex determination.

\section{Introduction}

Sex determination in the order Hymenoptera is based on arrhenotoky except in cases of secondarily thelytokous species. Hymenopteran males are usually haploid and females diploid, but in some species diploid males can be produced by inbred crosses. At the genetic level, several mechanisms have been proposed to explain sex determination (review in Crozier, 1977; Bull, 1983; Poirié et al., 1992).

The available data have demonstrated that sex determination is controlled by multiple alleles at a single locus in some hymenopteran species, e.g. Bracon hebetor, Ichneumonoidea (Whiting, 1943), Apis mellifera, Apoidea (Drescher \& Rothenbuhler, 1964) and A. cerana indica (Woyke, 1979), Solenopsis invicta, Formicoidea (Ross \& Fletcher, 1985) and Athalia rosae ruficornis, Tenthredinoidea (Naito \& Suzuki, 1991). In this one-locus multi-allele model, diploid females are considered as being heterozygous for two alleles while males can be obtained from unfertilized eggs (haploid-hemizygous for one sex allele) or from fertilized eggs (diploid-homozygous for one sex allele). In any single pair cross, a maximum of three alleles can

*Present address: Department of Entomology, Ain Shams University, Abassia, Cairo, Egypt.

Correspondence: G. Periquet. be involved, one paternal and two maternal. Sib-sib matings should therefore rapidly yield diploid males since 50 per cent of the diploids in each generation should be homozygous. Results of inbreeding experiments were consistent with these expectations in the few species quoted above but the failure to rapidly obtain diploid males in other Hymenoptera of the chalcidoidean superfamily such as Nasonia vitripennis (Whiting, 1960), Melittobia species (Schmieder \& Whiting, 1947) and Dinarmus vágabundus (RojasRousse et al., 1988) deprives this hypothesis of generality.

To explain this difficulty in producing diploid males, Crozier (1971) proposed a multi-locus multi-allele model in which individuals that are heterozygous for one or more of these loci are necessarily females while males are hemizygous or homozygous at all sex loci. In this view, the one-locus model appears to be a special case of the multi-locus model in which all but one of the loci are monomorphic.

Considering the importance of these models, both at the genetic and the evolutionary levels, more investigation is needed to determine the level of generality for other hymenopteran families. In Diadromus pulchellus, biparental males have been observed and found to be diploid (Hedderwick et al., 1985). Production of these diploid males by inbreeding, using several genetically different strains has been performed. The results of these experiments are presented here and show that 
sex determination in this species is congruent with the one-locus multi-allele model.

\section{Materials and methods}

\section{Strains}

Diadromus pulchellus is a solitary endoparasitoid of the Lepidoptera Acrolepiopsis assectella. In this experiment, a black-bodied wild strain (Siagne 83) collected in the south of France and a yellow-bodied strain carrying the recessive $j^{82}$ mutation were used (Hedderwick et al., 1985). The stocks were bred en masse, on host pupae, using the Lecomte and Thibout technique (1983). Briefly, the parasitoids were reared in cages at $25^{\circ} \mathrm{C}, 60$ per cent +10 per cent relative humidity (r.h.) during the $16 \mathrm{~h} /$ day photophase and at $15^{\circ} \mathrm{C}, 70$ per cent +10 per cent r.h. during scotophase.

For the breeding experiments involving one pair of parasitoids, 10 pupae of 24-hour-old Acrolepiopsis assectella were presented every day for 20 days to each Diadromus female for oviposition. The lepidopteran host strain was the standard stock bred in the laboratory (Auger \& Thibout, 1983).

In parallel, taking into account the allozyme polymorphism known in this species (Shaumer et al., 1978), analyses were performed with individuals from the wild strain, for the phosphoglucomutase system (two loci $P g m-1$ and $P g m-2$ with $F$ and $S$ alleles at each locus) and for the aldehyde oxydase locus no. $4(A O-4$, also di-allelic in our strains).

\section{Basic models and protocol of crosses}

According to the results of Hedderwick et al. (1985), males that are heterozygous for an enzymatic locus or for the body colour locus, are diploid and can be easily detected. The principle of the experiment therefore lies in the possibility of obtaining such diploid males from individual inbred crosses and in the comparison of their observed frequencies to the frequencies expected under the one-locus multi-allele model or under the two-locus multiple allele model.

In a first set of experiments, individual crosses involving a virgin female (isolated at the pupal stage) and a male randomly selected from the wild stock were performed. One virgin female of each progeny was back-crossed to her father. One week later, the parents were analysed for their enzymatic systems to detect crosses involving a heterozygous $F / S$ female at any locus. Ten independent families of this kind were obtained and their progeny were studied by counting the daughters and analysing the sons to determine their genotype at the enzymatic locus. Four classes were thus counted, giving the total number of females (a1), the numbers of $[F]$ males $(\mathrm{a} 2),[S]$ males $(\mathrm{a} 4)$ and heterozygous $F / S$ males $(\mathrm{a} 3)$. These observed $a j$ values were then compared with expectations by a classical chisquare test.

The expected values depend, of course, on the model chosen but also on the ability of hymenopteran females to produce unfertilized eggs developing into haploid males. Let $f$ be the frequency of fertilized eggs in a cross and $(1-f)$ that of unfertilized eggs. As $f$ is variable from cross to cross, it needs to be estimated in each case by a maximum likelihood function based on the sex determination model.

For the one-locus multi-allele model, Appendix 1 gives the expected proportion of the different classes in the progeny of the back-cross between one heterozygous female and her father. It is assumed that the sex locus and the enzymatic locus analysed are genetically independent. In this case, estimation of $f$ can be obtained by equations 1 and $1^{\prime}$, and the expected values deduced.

For the two-locus multi-allele model, a similar reasoning leads to the values given in Appendix 2. The $\mathrm{G}_{1}$ female is assumed to be heterozygous for both sex loci which are independent from each other and from the enzymatic locus. The estimate of $f$ is given by equations 2 and $2^{\prime}$, and the expected values deduced.

In a second set of experiments, crosses were performed between individuals from the wild strain and from the yellow mutant strain, to detect diploid males using body colour. The diagram of crosses is presented in Fig. 1. Parental crosses between one homozygous black female $\left(j^{+} / j^{+}\right)$and one yellow male $(j)$ gave $\mathrm{G}_{1}$ heterozygous black females. One of them $\left(j^{+} / j\right)$, backcrossed to her father $(j)$, yielded $\mathrm{G}_{2}$ black and yellow offspring of both sexes. From one of the $G_{2}$ yellow females $(j / j)$ thus obtained, crossed with one of its black brothers $\left(j^{+}\right)$, we finally obtained $\mathrm{G}_{3}$ black females $\left(j^{+} / j\right)$, yellow haploid males $(j)$ and black biparental males $\left(j^{+} / j\right)$ which are diploid and fully viable. Twenty-two such $G_{2}$ families were produced independently and their $G_{3}$ progeny were sexed and scored.

Under the one-locus multi-allele model, the transmission of the sex alleles and of the $j^{+}, j$ alleles in these crosses is presented in Fig. 2, assuming no linkage between the loci. The biparental black males of the $G_{3}$ generation are expected to occur at a 1:1 ratio with the black females. This ratio is of course expected to decrease for other models as diploid males become rarer when the number of sex loci increases. Under the two independent loci $\left(X 1\right.$ and $\left.X^{\prime} 1\right)$ multi-allele model, the expected ratio of diploid males to females is $1: 3$ in the $G_{3}$ generation (see Appendix 3). 
black strain

$19+$

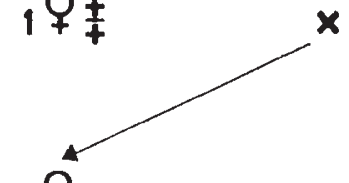

yellow strain

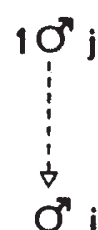

Parents

$\mathrm{G}_{1}$ ㅇ back crossed
Fig. 1 Diagram of crosses between black and yellow individuals of Diadromus pulchellus leading to the obtention of heterozygous diploid males.

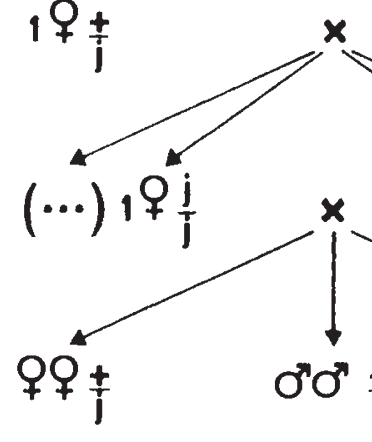

[black ] [black ]
Among

$G_{2}$ progeny

$G_{3}$ progeny

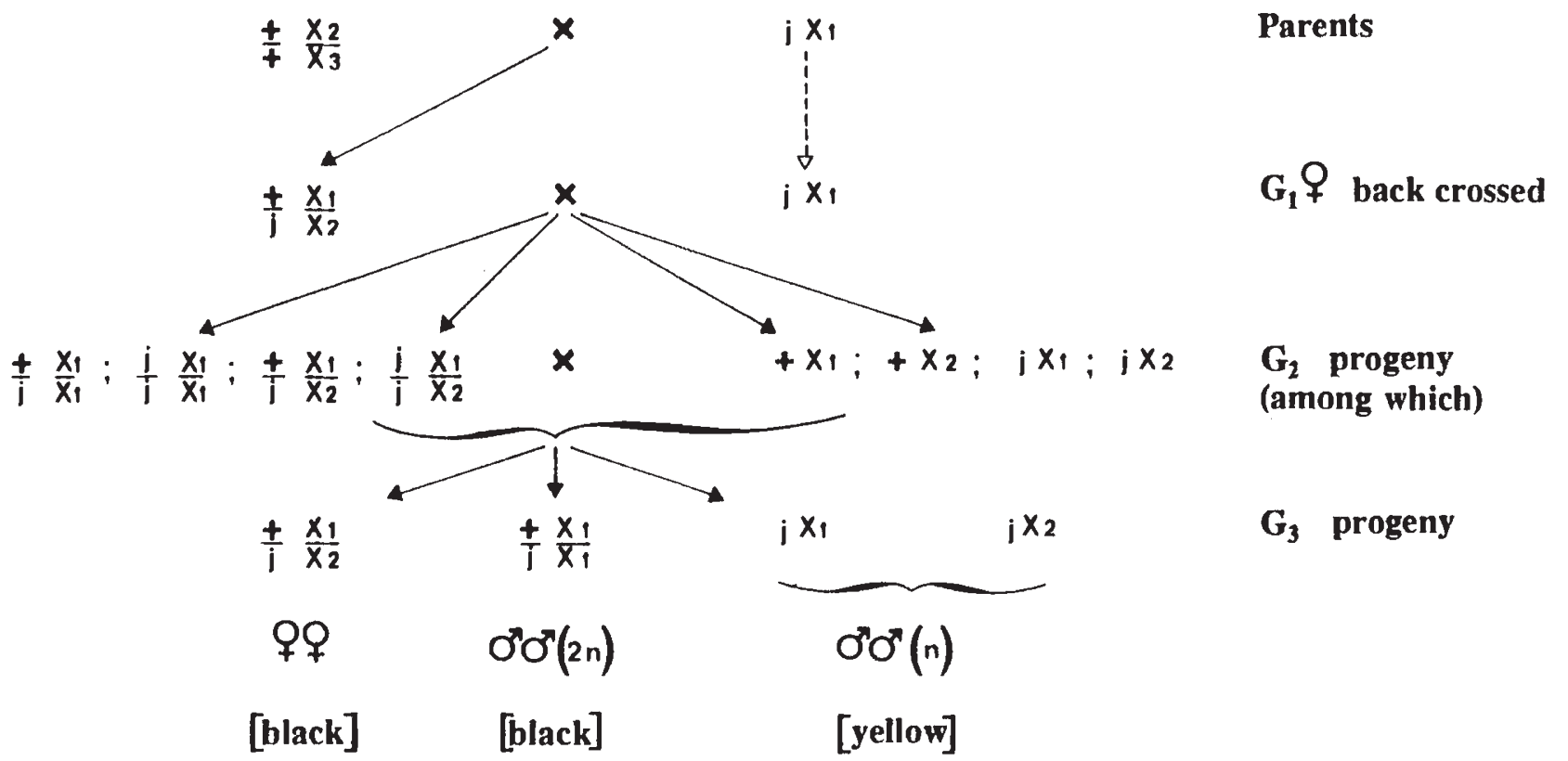

Fig. 2 Transmission of sexual alleles under the one-locus model and the obtention of diploid males in the crosses performed between black and yellow individuals of Diadromus pulchellus.

\section{Results}

\section{Experiments with the enzymatic systems}

From the 10 independent families, 13 individual backcrosses involving a heterozygous female and her father were used ( 3 of the $10 \mathrm{G}_{2}$ females being heterozygous for two enzymatic loci, their progeny were scored for each system). The progeny numbers are given in Table 1.

For each model, the estimate of $f$ and the chi-square values are given. The $f$ values, generally above 0.5 , are too variable to allow data pooling. Considering the chisquare values calculated, it appears clearly that the one-locus multi-allele model correctly fits the data (no significant value out of 13 ), whereas the two-locus 
model must be rejected ( 8 significant values out of 13 ). Most frequently, the two-locus model does not fit because the number of expected heterozygous males is lower than the number observed. This point confirms that the one-locus model is sufficient to interpret these data. Note that the quality of fit with the Pgm-1, Pgm-2 and $A o-4$ loci also suggests that the genetic independence between these loci and the sex locus can be accepted.

\section{Experiments with the body colour mutant strain}

The 22 inbred families independently obtained lead to $\mathrm{G}_{2}$ crosses between one yellow female $(j / j)$ and one of her black brothers $\left(j^{+}\right)$. In their progeny, black females, diploid black males and haploid yellow males were scored. Results are presented in Table 2. The mean frequency of yellow males $(1-f)$ was 0.40 in the $G_{3}$ progeny, leading to a direct estimate of fertilization at $f=0.60$, a value close to those obtained previously by the likelihood method. However, in each experiment, as black males are necessarily obtained from fertilized ova, their ratio to black females is independent of $f$. It is therefore possible to pool the data on the total (test of heterogeneity $\chi^{2}=10.8, \mathrm{~ns}$ ) in order to test the two sex determination models. Once again, it appears clearly that the one-locus multi-allele model provides the best fit for the data. In each family, the observed frequencies of females and diploid males are very similar and the total numbers agree with the $1: 1$ ratio $\left(\chi^{2}=0.18\right.$, ns) but not with the $1: 3$ ratio $\left(\chi^{2}=205.9^{* * *}\right)$. These results also point to the genetic

Table 1 Comparison of the observed proportions of the $G_{2}$ progeny resulting from back-crosses between heterozygous females and their fathers, to the proportion expected under the one-locus or the two-locus models of sex determination

\begin{tabular}{|c|c|c|c|c|c|c|c|c|c|c|}
\hline & \multirow[b]{2}{*}{ Cross no. } & \multirow[b]{2}{*}{$\Sigma$} & \multirow[b]{2}{*}{ 우 } & \multicolumn{3}{|c|}{$\mathrm{G}_{2}$ progeny } & \multicolumn{2}{|c|}{$\begin{array}{l}\text { One-locus } \\
\text { model }\end{array}$} & \multicolumn{2}{|c|}{ Two-locus model } \\
\hline & & & & $\circlearrowleft[F]$ & $\sigma^{*}[F S]$ & $\circlearrowleft[S]$ & $f$ & $\chi^{2}$ & $f$ & $\chi^{2}$ \\
\hline \multicolumn{11}{|c|}{ Pgm-1 locus } \\
\hline$F S \times F$ & 1 & 67 & 35 & 13 & 16 & 3 & 0.930 & 1.89 & 0.892 & $8.12^{* *}$ \\
\hline$F S \times F$ & 2 & 55 & 26 & 10 & 16 & 3 & 0.918 & 2.76 & 0.882 & $13.10^{* * *}$ \\
\hline \multicolumn{11}{|c|}{ Pgm-2 locus } \\
\hline$F S \times F$ & 1 & 67 & 35 & 15 & 16 & 1 & 0.974 & 0.45 & 0.939 & $10.85^{* * *}$ \\
\hline$F S \times F$ & 3 & 33 & 16 & 6 & 8 & 3 & 0.866 & 1.70 & 0.826 & $4.52^{*}$ \\
\hline$F S \times F$ & 4 & 20 & 4 & 5 & 3 & 8 & 0.416 & 1.97 & 0.384 & 3.28 \\
\hline$F S \times F$ & 5 & 53 & 16 & 15 & 4 & 18 & 0.462 & 2.58 & 0.421 & 1.40 \\
\hline$F S \times F$ & 6 & 48 & 17 & 18 & 3 & 10 & 0.564 & 1.91 & 0.489 & 0.85 \\
\hline$F S \times S$ & 7 & 45 & 24 & 2 & 6 & 13 & 0.906 & 2.17 & 0.821 & 2.73 \\
\hline$F S \times S$ & 8 & 68 & 13 & 18 & 9 & 28 & 0.439 & 0.57 & 0.378 & $5.74^{*}$ \\
\hline \multicolumn{11}{|c|}{ Ao4 locus } \\
\hline$F S \times S$ & 9 & 52 & 16 & 10 & 6 & 20 & 0.580 & 0.13 & 0.500 & 3.49 \\
\hline$F S \times S$ & 10 & 46 & 12 & 11 & 9 & 14 & 0.581 & 0.33 & 0.521 & $4.09^{*}$ \\
\hline$F S \times S$ & 7 & 45 & 24 & 0 & 10 & 11 & 1.000 & 0.24 & 1.000 & $11.33^{* * *}$ \\
\hline$F S \times S$ & 8 & 68 & 13 & 21 & 12 & 22 & 0.466 & 0.95 & 0.417 & $5.15^{*}$ \\
\hline
\end{tabular}

Table 2 Observed numbers of the $\mathrm{G}_{3}$ progeny involving sib-sib matings to generate diploid males. Under the one-locus model, the expected ratio of females to diploid males is $1: 1$, which agrees well with the data

\begin{tabular}{lrrrrrrrrrrrrrrrrrrrrrrrrrr}
\hline$G_{3}$ progeny & 1110 & \multicolumn{11}{c}{ Number of families } \\
\hline & 1 & 2 & 3 & 4 & 5 & 6 & 7 & 8 & 9 & 10 & 11 & 12 & 13 & 14 & 15 & 16 & 17 & 18 & 19 & 20 & 21 & 22 & 22 \\
Females & 23 & 12 & 10 & 13 & 15 & 20 & 7 & 18 & 9 & 15 & 19 & 25 & 12 & 15 & 15 & 16 & 19 & 13 & 22 & 9 & 10 & 19 & 336 \\
Diploid males & 25 & 13 & 7 & 12 & 12 & 18 & 17 & 10 & 10 & 14 & 17 & 16 & 16 & 15 & 13 & 16 & 18 & 14 & 25 & 10 & 10 & 17 & 325 \\
Haploid males & 11 & 31 & 20 & 20 & 18 & 20 & 17 & 20 & 15 & 25 & 38 & 21 & 17 & 20 & 14 & 21 & 17 & 21 & 26 & 10 & 17 & 20 & 439 \\
\hline
\end{tabular}


independence of the yellow body colour locus from the sex locus.

\section{Discussion}

To date, male diploidy has been reported only in several hymenopteran genera from the 'primitive' suborder of Symphyta (sawfly) to the more recent family of
Apoidea (bee) (Crozier, 1977; Ross \& Fletcher, 1985; Kukuk \& May, 1990; Naito \& Suzuki, 1991; Poirié et al., 1992). A summary of these results is given in Table 3 where the species are grouped at the superfamily level.

Diploid males have been found in every group studied. The one-locus model has been attested at least once in these groups except in the Chalcidoidea which

Table 3 Occurrence of diploid males in hymenopteran species studied to date. The one-locus model is proposed when it fits the data. (A question mark is given when the data are not fully conclusive.)

\begin{tabular}{|c|c|c|}
\hline Taxon & $\begin{array}{l}\text { Occurrence of } \\
\text { diploid males }\end{array}$ & $\begin{array}{l}\text { One-locus } \\
\text { model }\end{array}$ \\
\hline \multicolumn{3}{|l|}{ Sub-order Symphyta } \\
\hline \multicolumn{3}{|l|}{ Tenthredinoidae } \\
\hline Athalia rosae & Larger than haploids & Yes \\
\hline Neodiprion nigroscutum & $\begin{array}{l}\text { Heavier than haploids } \\
\text { Nearly sterile }\end{array}$ & Yes \\
\hline \multicolumn{3}{|l|}{ Sub-order Apocrita } \\
\hline \multicolumn{3}{|l|}{ Infra-order Parasitica } \\
\hline \multicolumn{3}{|l|}{ Ichneumonoidea Braconidae } \\
\hline Bracon hebetor & $\begin{array}{l}\text { Cell size bigger } \\
\text { Less viable and fertile }\end{array}$ & Yes \\
\hline Micropletis croceipes & Yes & $?$ \\
\hline \multicolumn{3}{|c|}{ Ichneumonoidea Ichneumonidae } \\
\hline Diadromus pulchellus & $\begin{array}{l}\text { Sterile } \\
\text { Larger than haploids }\end{array}$ & Yes \\
\hline Bathyolectes curculionis & Yes & ? \\
\hline \multicolumn{3}{|l|}{ Chalcidoidea } \\
\hline Nasonia vitripennis & $\begin{array}{l}\text { Arisen by mutation, fertile } \\
\text { Larger than haploids }\end{array}$ & $?$ \\
\hline Pteromalus puparum & No & $?$ \\
\hline Mellitobia spp. & No & No \\
\hline Dinarmus vagabundus & No & No \\
\hline Cothonaspis boulardi & No & No \\
\hline Leptopilina heterotoma & No & No \\
\hline \multicolumn{3}{|l|}{ Proctotrupoidea } \\
\hline Telonomus fariae & No & No \\
\hline \multicolumn{3}{|l|}{ Infra-order ACULEATA } \\
\hline \multicolumn{3}{|l|}{ Formicoidea } \\
\hline Solenopsis invicta & Yes & Yes (?) \\
\hline Lasius alienus/niger & Yes & $?$ \\
\hline Formica pressilabris & Yes & ? \\
\hline Rhytidoponera spp. & Yes & ? \\
\hline Pseudolasius emeryi & Yes & ? \\
\hline \multicolumn{3}{|l|}{ Apoidea } \\
\hline Apis mellifera & Viable, eaten by workers & Yes \\
\hline Apis cerana & Yes & Yes (?) \\
\hline Bombus atratus & Viable & $?$ \\
\hline Melipona quadrifasciata & Yes & ? \\
\hline Trigona quadrangula & Yes & ? \\
\hline Augochorella striata & Yes & $?$ \\
\hline Lasioglossum zephyrum & Yes & Yes (?) \\
\hline
\end{tabular}


seems to possess a different sex-determining mechanism.

The present analyses of crosses leading to the generation of diploid males in $D$. pulchellus allow us to state that the one-locus model of sex determination is the most plausible in this species of the family Ichneumonidae. These data, the first reported in favour of this model in Ichneumonidae, must be associated with the similar results obtained from the related Braconidae (Whiting, 1943). Taken together, these conclusions reinforce the generality of the one-locus model of sex determination in the Ichneumonoidea superfamily and raise the question of its generality for the entire order of Hymenoptera.

Within other hymenopteran species having a single sex locus, estimates of 19 sex alleles have been reported for Apis mellifera (Adams et al., 1977), 9 for Bracon hebetor (Whiting, 1960) and about 15 for Solenopsis invicta (Ross \& Fletcher, 1985). In D. pulchellus, the presence of 4-5 per cent of heterozygous males for the Ao-4 and the Pgm-2 locus respectively, in samples collected from natural populations (Hedderwick et al., 1985) suggests a similar number of sex alleles. Actually, if we consider that the equilibrium frequency of each allele is $1 / n$, where $n$ is the number of alleles (Bull, 1983), the expected frequency of diploid males issued from fertilized zygotes will be $n(1 / n)^{2}=1 / n$ in a population panmictic for this locus. The relative frequency of diploid males $(d)$ among the males of the entire population depends on the proportion of fertilized zygotes $(f)$ and will be $d=(f / n) \mid$ $(f / \mathrm{n}+1-f)$. With an average value of $f=0.50$, the percentage of diploid males will range from 13 to 7 per cent, with $n$ varying from 10 to 20 . If we assume that the population lies at the Hardy-Weinberg equilibrium for a di-allelic locus (e.g. an enzymatic marker), the frequency of heterozygous males amoung the males will be $h=(2 p q f / n) /(f / n+1-f)$, from which is deduced the value of $d=h / 2 p q$.

For Diadromus pulchellus, Hedderwich et al. (1985) found the frequency of heterozygous males to be 0.049 at the Pgm-2 locus (with the $F$ allele at 0.63 ) and 0.038 at the $A o-4$ (with the $F$ allele at 0.39). From these values, we can deduce that the percentage of diploid males in the sampled population is about 9 per cent, which gives a provisional estimate of $\sim 15$ alleles for the sex locus of $D$. pulchellus.

This high number of alleles at the sex locus lowers the probability of the occurrence of diploid males, which are generally less fertile than haploid males and may even be sterile. In natural populations, selection will therefore tend to increase the number of sex alleles in species with the one-locus system of sex determination whereby some sex alleles can be lost by genetic drift. Adoption of the multi-locus system would constitute another evolutionary strategy to avoid the occurrence of diploid males by sib-mating. In Hymenoptera, the one-locus sex determination mechanism is considered to be ancestral to the multi-locus mechanism (Bull, 1981). The fact that the one-locus model applies to species in widely separated groups, from the most primitive sawflies to the specialized Ichneumonoids, the ants and bees, corroborates this hypothesis. The multi-locus system might have evolved as a means to prevent the effects of inbreeding in species, such as Nasonia vitripennis and Melittobia spp, that use this mode of reproduction. A contrasting hypothesis reverses this chronology, suggesting that these species might have adopted sib-matings only after the development of the multi-locus system. Note that the so-called one-locus model might in fact correspond to a series of tandemly repeated genes, closely linked on a chromosome and undetectable at the present level of genetic analysis. Under this last hypothesis, a general picture of the evolution of sex determination in Hymenoptera can be drawn, starting from an ancestral single locus, evolving in a closely-linked multigenic family and ending in the dispersion of some of these genes onto other chromosomes, thus leading to a multi-locus system.

\section{Acknowledgements}

We thank M. H. Hamelin and J. C. Landré for their technical assistance. This work was supported by grants from the Ministère de l'Education Nationale (DRED:Evolution) and the CNRS (URA 1298).

\section{References}

ADAMS, J., ROTHMAN, E. D., KEER, W. E. AND PAULINO, Z. L. 1977. Estimation of the number of sex alleles and queen matings from diploid male frequencies in a population of Apis mellifera. Genetics, 86, 583-596.

AUGER, J. AND THIBOUT, E. 1983. Spécificité des substances non volatiles des allium responsables de la ponte de la teigne du poireau, Acrolepiopsis assectella (Lepidoptera). Ent. Exp. Appl., 34, 71-77.

BULL, J. J. 1981. Coevolution of haplo-diploidy and sex determination in the Hymenoptera. Evolution, 35, 568-580.

BULL, I. J. 1983. Evolution of Sex Determining Mechanisms. Benjamin/Cummings, Menlo Park, CA.

CROZIER, R. H. 1971. Heterozygosity and sex determination in haplo-diploidy. Amer. Nat., 105, 399-412.

CROZIER, R. H. 1972. Evolutionary genetics of the Hymenoptera. Ann. Rev. Entomol., 22, 263-288.

DRESCHER, w. AND ROTHENBUHLER, w. C. 1964. Sex determination in the honey bee. J. Hered., 55, 91-96.

HEDDERWICK, M. P., EL AGOZE, M., GARAUD, P. AND PERIQUET, G. 1985. Mise en évidence de mâles hétérozygotes chez 
l'hyménoptère Diadromus pulchellus (Ichneumonide). Génét. Sél. Evol., 17, 303-310.

KUKUK, P. F. AND MAY, B. 1990. Diploid males in a primitively eusocial bee, Lasioglossum (Dialictus) zephyrum (Hymenoptera: Halictidae). Evolution, 44, 1522-1528.

LECOMTE, C. AND THiBout, E. 1983. Analyse, en olfactométrie tubulaire, de l'influence de différents stimulants olfactifs dans la recherche de l'hôte par Diadromus pulchellus (Hym. Ichneumonidae). Entomophaga, 28, 217-226.

NAITO, T. AND SUZUK1, H. 1991. Sex determination in the sawfly, Athalia rosae ruficornis (Hymenoptera): occurrence of triploid males. J. Hered., 82, 101-104.

POIRIE, M., PERIQUET, G. AND BEUKEBOOM, L. W. 1992, Arrhenotoky: the hymenopteran way of determining sex. Seminars in Developmental Biology, 3, 357-361.

ROJAS-ROUSSE, D., ESLAM1, J. AND PERIQUET, G. 1988. Reproductive strategy of Dinarmus vagabundus Timb. (Hym., Pteromalidae): real sex ratio, sequence of emitting diploid and haploid eggs and effects of inbreeding on progeny. $J$. Appl. Ent., 106, 276-285.

ROSS, K. G. AND FLETCHER, D. J. 1985. Genetic origin of male diploidy in the fire ant, Solenopsis invicta (Hymenoptera: Formicidae), and its evolutionary significance. Evolution, 39, 888-903.

SCHAUMAR, N., ROJAS-ROUSSE, D. AND PASTEUR, N. 1978. Allozyme polymorphism in the parasitic hymenoptera Diadromus pulchellus WSM (Ichneumonidae). Genet. Res., 32, 47-54.

SCHMIEDER, R. G. AND WHITING, P. W. 1947. Reproductive economy in the chalcidoid wasp Melittobia. Genetics, 32, 29-37.

whitiNG, P. w. 1943. Multiple alleles in complementary sex determination of Habrobracon. Genetics, 28, 365-382.

whiting, P. w. 1960. Polyploidy in Mormoniella. Genetics, 45, 949-970.

woyke, J. 1979. Sex determination in Apis cerana indica. $J$. Apicult. Res., 18, 122-127.

Appendix 1 One-locus model of sex determination. Expected proportions of females, haploid males and diploid males in the progeny from a backcross between a female heterozygous for an enzymatic locus and her father

$$
1 \% \frac{S}{S} \frac{X_{2}}{X_{3}} \times 1{ }^{\circ} F X_{1} \text { from the base population }
$$

Selected back-cross: $1 \% \frac{F}{S} \frac{X_{1}}{X_{2}} \times 1{ }^{\circ} F X_{1}$ (the father)

Formation of the $\mathrm{G}_{2}$ progeny:

\begin{tabular}{|c|c|c|c|c|}
\hline Ova & $F X_{1}$ & $F X_{2}$ & $S X_{1}$ & $S X_{2}$ \\
\hline $\begin{array}{l}f: \text { fertilization }\left(\text { sperm } F X_{1}\right) \\
(1-f) \text { : no fertilization }\end{array}$ & $\begin{array}{l}\text { On} 2 n[F] \\
\text { on } n[F]\end{array}$ & $\begin{array}{l}O[F] \\
O n[F]\end{array}$ & $\begin{array}{l}\text { on } 2 n[F S] \\
\text { on } n[S]\end{array}$ & 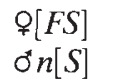 \\
\hline Analysis of the four classes & $\underset{\wp}{\mathrm{e} \mathrm{G}_{2}}$ pro & $\varnothing[F]$ & $\sigma^{\circ}[F S]$ & $\varnothing[S]$ \\
\hline $\begin{array}{l}\text { Observed number } \\
\text { Expected proportion }\end{array}$ & $\begin{array}{l}a_{1} \\
f / 2\end{array}$ & $\begin{array}{l}\mathrm{a}_{2} \\
(2-f) / 4\end{array}$ & $\begin{array}{l}a_{3} \\
f / 4\end{array}$ & $\begin{array}{l}a_{4} \\
(1-f) / 2\end{array}$ \\
\hline
\end{tabular}

Maximum likelihood estimate of $f$ given by the solution of:

$$
\begin{aligned}
& \text { for a back-cross } Q F / S \times \sigma^{\prime} F \\
& f^{2}\left(\mathrm{a}_{1}+\mathrm{a}_{2}+\mathrm{a}_{3}+\mathrm{a}_{4}\right)-f\left(3 \mathrm{a}_{1}+\mathrm{a}_{2}+3 \mathrm{a}_{3}+2 \mathrm{a}_{4}\right)+2\left(\mathrm{a}_{1}+\mathrm{a}_{3}\right)=0 \\
& \text { for a backcross } \& F / S+\sigma^{\prime} S \\
& f^{2}\left(\mathrm{a}_{1}+\mathrm{a}_{2}+\mathrm{a}_{3}+\mathrm{a}_{4}\right)-f\left(3 \mathrm{a}_{1}+2 \mathrm{a}_{2}+3 \mathrm{a}_{3}+\mathrm{a}_{4}\right)+2\left(\mathrm{a}_{1}+\mathrm{a}_{3}\right)=0 \\
& \text { with }(1-f) / 2 \text { expected } \sigma^{\circ}[F] \text { and }(2-f) / 4 \text { expected } o^{4}[S]
\end{aligned}
$$

$F, S=$ alleles at the enzymatic locus, $X_{\mathrm{i}}=$ alleles at the sex locus, $f=$ frequency of fertilized eggs. 
Appendix 2 Two-locus model of sex determination. Expected proportions of females, haploid males and diploid males in the progeny from a backcross between a female heterozygous for an enzymatic locus and her father

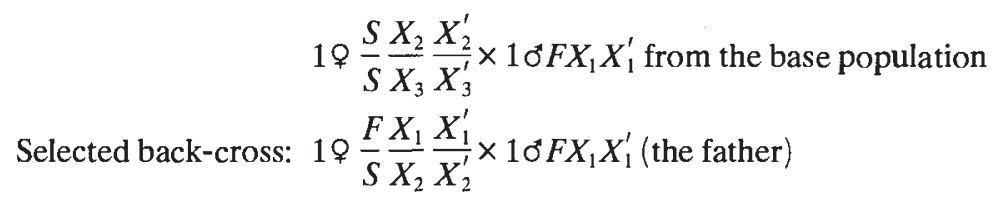

Formation of the $\mathrm{G}_{2}$ progeny:

\begin{tabular}{|c|c|c|c|}
\hline Ova & $\begin{array}{l}f: \text { fertilization } \\
\left(\text { sperm } F X_{1} X_{1}^{\prime}\right)\end{array}$ & & $\begin{array}{l}(1-f) \text { : } \\
\text { no fertilization }\end{array}$ \\
\hline$F X_{l} X_{1}^{\prime}$ & $\sigma^{2} 2 n[F]$ & & ơn $[F]$ \\
\hline$F X_{1} X_{2}^{\prime}$ & $\odot[F]$ & & on $n[F]$ \\
\hline$F X_{2} X_{1}^{\prime}$ & $q[F]$ & & on $n[F]$ \\
\hline$F X_{2}^{\prime} X_{2}^{\prime}$ & $q[F]$ & & on $[F]$ \\
\hline$S X, X_{I}^{\prime}$ & ơ $2 n[F S]$ & & on $n[S]$ \\
\hline$S X_{1}^{\prime} X_{2}^{\prime}$ & Q $[F S]$ & & on $[S]$ \\
\hline$S X_{2} X_{1}^{i}$ & $\wp[F S]$ & & on $n[S]$ \\
\hline$S X_{2} X_{2}^{\prime}$ & $[F S]$ & & on $[S]$ \\
\hline \multicolumn{4}{|c|}{ Analysis of the four classes in the $G_{2}$ progeny } \\
\hline & ९ $\quad \sigma[F]$ & $\sigma^{*}[F S]$ & $\sigma^{\prime}[S]$ \\
\hline Observed & $\mathrm{a}_{2}$ & $a_{3}$ & $a_{4}$ \\
\hline Expected proportion & $(4-3 f) / 8$ & $f / 8$ & $(1-f) / 2$ \\
\hline
\end{tabular}

Maximum likelihood estimate of $f$ given by the solution of:

$$
\begin{aligned}
& \text { for a back-cross } \& F / S \times \sigma^{\prime \prime} F \\
& 3 f^{2}\left(\mathrm{a}_{1}+\mathrm{a}_{2}+\mathrm{a}_{3}+\mathrm{a}_{4}\right)-f\left(7 \mathrm{a}_{1}+3 \mathrm{a}_{2}+7 \mathrm{a}_{3}+4 \mathrm{a}_{4}\right)+4\left(\mathrm{a}_{1}+\mathrm{a}_{3}\right)=0 \\
& \text { for a back-cross } \& F / S \times \sigma^{\prime} S \\
& 3 f^{2}\left(\mathrm{a}_{1}+\mathrm{a}_{2}+\mathrm{a}_{3}+\mathrm{a}_{4}\right)-f\left(7 \mathrm{a}_{1}+4 \mathrm{a}_{2}+7 \mathrm{a}_{3}+3 \mathrm{a}_{4}\right)+4\left(\mathrm{a}_{1}+\mathrm{a}_{3}=0\right. \\
& \text { with }(1-f) / 2 \text { expected } o^{\prime}[F] \text { and }(4-3 f) / 8 \text { expected o }[S]
\end{aligned}
$$

$F, S=$ alleles at the enzymatic locus, $X_{\mathrm{i}}=$ alleles at the sex locus, $f=$ frequency of fertilized eggs.

Appendix 3 Under the two independent locus $(X 1$ and $\left.X^{\prime} 1\right)$ multi-allele model, the expected ratio of diploid males in the $\mathrm{G}_{3}$ generation can be calculated as follows. Take a $\mathrm{G}_{1}$ back-cross between a male $j ; X 1 ; X^{\prime} 1$ and a female $+/ j$, heterozygous for the two sexual loci $X 1 X 2 ; X^{\prime} 1 X^{\prime} 2$ (which is generally true as the female is generated by random crosses from the base population). If we assume that a female must be heterozygous at least at one sex locus, three types of yellow females are generated, with the same frequency, at the $G_{2}$ generation $\left(X 1 X 1 ; X^{\prime} 1 X^{\prime} 2-X 1 X 2 ; X^{\prime} 1 X^{\prime} 1-\right.$ $\left.X 1 X 2 ; X^{\prime} 1 X^{\prime} 2\right)$ and four types of black males $\left(X 1 X^{\prime} 1\right.$ $\left.X 1 X^{\prime} 2-X_{2} X_{I}^{\prime}-X 2 X^{\prime} 2\right)$. The 12 possible random crosses of $G_{2}$ individuals therefore will involve either females heterozygous for both sex loci (probability $1 / 3$ ) or for only one sex locus (probability $2 / 3$ ). In the first case, diploid males and females are expected at a 1:3 ratio in the $\mathrm{G}_{3}$ generation. In the second case, this ratio is expected to be $1: 1$ if the $G_{2}$ female has two alleles in common with the $\mathrm{G}_{2}$ male (e.g. $X 1 X 1 ; X^{\prime} 1 X^{\prime} 2$ crossed with $X^{\prime} 1 X^{\prime} 2$ ), but no diploid males are expected if the $\mathrm{G}_{2}$ female has only one allele in common with the $\mathrm{G}_{2}$ male (e.g. $X 1 X 1 ; X^{\prime} 1 X^{\prime} 2$ crossed with $X 2 X^{\prime} 1$ ). As the 12 possible $G_{2}$ crosses are equiprobable, the expected ratio of diploid males to females is $1: 3$ in the global $G_{3}$ generation. 